\title{
Decline in relative growth rate of 3 juvenile radiata pine clones subjected to varying competition levels in Canterbury, New Zealand
}

\author{
Balozi B. KIRONGO ${ }^{a *}$, Euan G. MASON ${ }^{b}$ \\ ${ }^{a}$ Research Scientist at the Kenya Forestry Research Institute (KEFRI), Gede Regional Research Centre, PO Box 201, Malindi, Kenya \\ b Associate Professor, School of Forestry, University of Canterbury, Private Bag 4800, Christchurch, New Zealand
}

(Received 24 June 2002; accepted 7 August 2003)

\begin{abstract}
Relative growth rate (RGR) is the ratio of growth to size at the beginning of the growth period. The assumption that RGR is constant, has been the subject of debate for a long time. In this study, the changes in mean RGR $(R G R)$ of 3 clones of Pinus radiata D. Don, grown under varying weed competition levels (complete weeding, weeding of $2 \mathrm{~m}$ diameter circles, weeding of $1 \mathrm{~m}$ diameter circles, and no weeding), were quantified for 3 consecutive years. $\overline{R G R}$ was calculated each winter, using the morphological and physiological characteristics of RGR change which quantified as follows:

$$
R G R=\underbrace{\frac{d W}{d T} \times \frac{1}{L A}}_{U L R} \times \underbrace{\frac{L A}{L w}}_{S L A} \times \underbrace{\frac{L w}{W}}_{L W R}
$$

where: $\mathrm{LA}=$ leaf area, $\mathrm{Lw}=$ leaf weight, $\mathrm{W}=$ dry weight of the plant, SLA $=$ specific leaf area, i.e. the ratio of area and leaf weight, $\mathrm{LWR}=$ leaf weight ratio, i.e. the ratio of total leaf weight of the plant and the total dry weight of the plant, $\mathrm{T}=$ time (age), ULR $=$ unit leaf rate. The results showed that the unweeded control treatment had the lowest absolute RGR. $\overline{R G R}$ declined with time and tree size in all the weeded treatments, but increased in the control. The theory that $\overline{R G R}$ is constant ( $\mathrm{RGR}=\mathrm{k}$ model) is shown to be false, as it varies with both time and tree size. Changes in $\overline{R G R}$ during the period studied were best described by an exponential decay function: $R G R=a+b \times \exp (-c W)$. Clonal differences were also demonstrated: clone 3 showed a lower RGR than the other two clones. This was due to the increased LWR and LAR, leaf area ratio (SLA $\times$ LWR) of this clone. The main reason for mean RGR decline were: (1) reduced ULR with age and size of the plants, (2) changes in allometry and (3) physiological aging which might have accentuated self shading effects. Tree size influenced RGR changes more than age. This study aims to dispel the notion of a constant RGR, and at the same time explains the reasons for the decline o this parameter in young trees.
\end{abstract}

RGR / clones / weeding / LAR / ULR

Résumé - Baisse du taux de croissance relative de 3 jeunes clones de pin radiata soumis à divers niveaux de compétition, à Canterbury, Nouvelle Zélande. Le taux de croissance relative (RGR) est le rapport entre la croissance et la taille en début de période de croissance. L'hypothèse selon laquelle RGR serait constant a été l'objet depuis longtemps de débats dans divers endroits. Dans cette étude, on a quantifié, pendant 3 années consécutives, les variations de RGR moyen $(\overline{R G R})$ de 3 clones de Pinus radiata D. Don soumis à divers niveaux de compétition (désherbage complet, désherbage d'un cercle de $2 \mathrm{~m}$ de diamètre, désherbage de $1 \mathrm{~m}$ de diamètre, pas de désherbage). $\bar{R} G R$ a été calculé, chaque hiver, à partir de caractéristiques morphologiques et physiologiques de l'évolution du RGR, qui ont été quantifiées comme suit :

$$
R G R=\underbrace{\frac{d W}{d T} \times \frac{1}{L A}}_{U L R} \times \underbrace{\frac{L A}{L w}}_{S L A} \times \underbrace{\frac{L w}{W}}_{L W R}
$$

$\mathrm{LA}=$ surface foliaire totale du plant, $\mathrm{Lw}=$ biomasse foliaire totale du plant, $\mathrm{W}=$ biomasse totale du plant, SLA = surface foliaire spécifique, c'est-à-dire rapport entre la surface et la biomasse des feuilles, LWR = rapport de biomasse foliaire, c'est-à-dire rapport entre la biomasse foliaire totale du plant et la biomasse totale du plant, T = âge, ULR = efficience folaire unitaire, c'est-à-dire accroissement en biomasse totale du plant rapporté à la surface foliaire. Les résultats obtenus montrent que le RGR est le moins élevé en valeur absolue pour le traitement témoin sans désherbage. $\overline{R G R}$ diminue dans le temps et avec la hauteur des arbres dans tous les traitements avec désherbage alors qu'il augmente pour le témoin. L'hypothèse d'un $\overline{R G R}$ constant ( $\mathrm{RGR}=\mathrm{k}$ modèle) est mise en défaut car il varie dans le temps et avec la hauteur des arbres. L'évolution de $R G R$ pendant la période en cause est mieux décrite par une fonction exponentielle décroissante: $R G R=a+b \times \exp (-c W)$. On a mis en évidence des différences d'évolution de RGR selon les clones, le clone 3 présentant un RGR inférieur à celui des deux autres. Ceci est dû à une valeur supérieure de LWR et de LAR $($ SLA $\times$ LWR) de ce clone. Les principales raisons de la baisse du RGR moyen sont : (1) décroissance de ULR avec l'âge et la taille des plants, (2) changements allométriques, (3) vieillissement physiologique pouvant accentuer les effets d'auto-ombrage. La taille des arbres joue un rôle plus important que l'âge sur les changements de RGR. Cette étude contribue à supprimer la notion d'un RGR constant tout en fournissant les raisons expliquant la baisse de ce paramètre chez les jeunes arbres.

RGR / clones / désherbage / LAR / ULR

\footnotetext{
*Corresponding author: kefrigede@ africaonline.co.ke, balozibk@hotmail.com
} 


\section{INTRODUCTION}

Research in plant growth analysis, especially the approaches of estimating plant production efficiency, and the effects of plant size on dry matter production efficiency, i.e. relative growth rate (RGR), has interested growth analysts for a long time. Relative growth rate [3] or efficiency index [2] is defined as the "ratio of growth of an organism to its initial size" [7, 9, 11] i.e.

$$
R G R=\frac{d W}{d T} \times \frac{1}{W} .
$$

Based on the assumption that growth is directly proportional to size:

$$
\frac{d W}{d T}=k \times W
$$

the equation implies an exponential size-age relationship:

$$
W=\exp (k \times T),
$$

where, $\mathrm{W}=$ plant dry weight, $\mathrm{T}=$ age and $k$ is a constant.

Mason et al. [17] argued that the equation (3) was unsuitable for use in young, "free growing" trees due to its inflexibility, while South [21] found that it rarely described actual tree growth data. Mason et al. [17] suggested that functions, which allowed RGR to vary with both time and tree size, were more rational. South [21] further reported that even where growth was exponential, initial size had to be set to zero to give constant RGR, an unlikely event in real life. He gave several examples of seedlings growing according to the same general curve but with different initial sizes ending up with different RGRs. This implied that the morphological and physiological states of the seedlings influenced their RGR, especially through effects on dry matter production rates. This is supported by others e.g. Menzies et al. [19] and Beets and Pollock [1] who reported chronological age to be of little importance compared to physiological age in determining dry matter accumulation.

Over the decades several researchers have used mean relative growth rate as an approximation of plant dry matter production efficiency $[6,9,11,14,25]$. Other researchers have used it to remove size-related differences [7, 11, 23]. However, the biological reasons for constant RGR and/or use of RGR to remove size-related differences have been questioned [4, 5, 17, 21, 22]. For example, Britt et al. [4] revealed that mean RGR did not remove size-related differences. They suggested that mean RGR be compared on an initial size basis rather than at equivalent ages.

Reported decreases in RGR with plant size have been attributed mainly to increases in structural material of little photosynthetic value [1], changes in allometry, especially selfshading [4] and physiological ageing [19]. Blackman [2] suggested that RGR would remain constant provided that unit leaf rate (ULR) and leaf area ratio (LAR) remained constant. Unit leaf rate [3] or net assimilation ratio [10] is defined as the "rate of dry matter increase per unit leaf area", i.e. [9]

$$
U L R=\frac{d W}{d T} \times \frac{1}{L A} .
$$

LAR on the other hand, is defined as the "ratio of total tree leaf area to total tree dry weight"; i.e. [9]

$$
L A R=\underbrace{\frac{L A}{L w}}_{S L A} \times \underbrace{\frac{L w}{W}}_{L W R}=\frac{L A}{W},
$$

where, $\mathrm{LA}=$ leaf area, $\mathrm{Lw}=$ leaf weight, $\mathrm{W}=$ plant dry weight, SLA = specific leaf area which is the ratio of leaf area to leaf weight, while LWR = leaf weight ratio and is defined as the ratio of total plant foliage weight to plant dry weight.

The mean RGR equation [9], has the disadvantage that it does not delve in to the possible physiological and morphological determinants of growth. Evans [9] used an expansion form of the equation to include LA, Lw and W; thus:

i.e.

$$
R G R=\frac{d W}{\underbrace{d T}_{U L R} \times \frac{1}{L A}} \times \underbrace{\frac{L A}{L w}}_{S L A} \times \underbrace{\frac{L w}{W}}_{L W R} ;
$$

$$
R G R=S L A \times L W R
$$

because LAR $=$ SLA $\times$ LWR (see Eq. (5)).

In this study the changes in mean RGR of 3 clones of radiata pine growing in four varying competition levels were evaluated for 3 years by quantifying the physiological and morphological changes using the RGR expansion (Eq. (6)) with the following main objectives:

1. to show which of the postulates for constant RGR (i.e. constant ULR and constant LAR) were breached;

2. to model the variation in RGR with time and tree size using the $\mathrm{RGR}=k$ model and models allowing for changes in tree size and age;

3. to study the effects of varying competition levels and the effects of genotype on mean RGR.

\section{MATERIALS AND METHODS}

This study was set up in September 1996 in Dunsandel, a dry site on the Canterbury plains, New Zealand. It was a competition-by-genotype experiment. Average annual rainfall at the site was $600 \mathrm{~mm}$. The main weed species were remnants of pasture especially white clover (Trifolium repens), sorrel (Rumex acetosella) and Italian rye grass (Lolium multiflorum). During the 2nd growing season there was a severe drought.

\subsection{Experimental design and layout}

The experiment was designed in randomized complete blocks and laid out in split-plots in 3 replications. Trees were planted at nominal spacings of $3 \times 3 \mathrm{~m}$. Weeding treatments formed the main plots while 3 (out of a possible 7) clones were the sub-plots. The weeding treatments were:

1. complete weeding equivalent to $9 \mathrm{~m}^{2}$ (Wc9) of weed-free area around each tree;

2. $2 \mathrm{~m}$ diameter circular weed-free spots equivalent to $3.14 \mathrm{~m}^{2}$ (Wc3);

3. $1 \mathrm{~m}$ diameter spots equivalent to $0.75 \mathrm{~m}^{2}$ weed-free area $(\mathrm{Wc} 0.75)$ around each tree;

4. a control (Wc0.03) which received $0.03 \mathrm{~m}^{2}$ weed-free area $(20 \mathrm{~cm}$ diameter spots) only at time of planting. 
The three clones (designated $\mathrm{Cl} 1, \mathrm{Cl} 2$ and $\mathrm{Cl} 3$ henceforth) used in the study were clone 1 (slowest grower of the seven clones in year 1), clone 2 (intermediate growth) and clone 3 (fastest growing of the seven clones in year 1). Main plots were planted with 70 seedlings in 7 lines of 10 trees of each clone. One row of surround received similar weeding treatments as the main plots. Weed control was achieved using a mixture of herbicides; terbuthylazine $(7.5 \mathrm{~kg}$ active ingredients, a.i.), haloxyfop (300 g a.i.) and clopyralid (900 g a.i.) all dissolved together in 250 litres of water to the hectare. Subsequent weed control was done whenever necessary. For more information on materials and methods refer to Mason and Kirongo [16].

\subsection{Quantifying terms of the RGR expansion}

Relative growth rate was calculated in winter of each year (at ages 1,2 and 3) by evaluating the terms in the RGR expansion;

$$
R G R=U L R \times L A R
$$

[9], [terms as defined earlier in Eqs. (4) and (5)].

Annual mean Unit leaf rate $(\overline{U L R})$ was given by;

$$
\overline{U L R}=\frac{W_{2}-W_{1}}{T_{2}-T_{1}} \times \frac{\log \left(L A_{2}\right)-\log \left(L A_{1}\right)}{L A_{2}-L A_{1}},
$$

(terms as defined earlier).

This is because:

$$
\begin{aligned}
\frac{\log \left(L A_{2}\right)-\log \left(L A_{1}\right)}{L A_{2}-L A_{1}} & =\frac{d \log (L A)}{d t} \times \frac{d t}{d(L A)} \\
& =\frac{1}{L A} \times \frac{d(L A)}{d t} \times \frac{d t}{d(L A)}=\frac{1}{L A} .
\end{aligned}
$$

Annual mean LAR was calculated thus,

$$
\overline{L A R}=\frac{L A_{2} / W_{2}+L A_{1} / W_{1}}{2} ;
$$

where, $\mathrm{LA}_{1}, \mathrm{LA}_{2}=$ leaf area of the tree at the start and end of the study period, and $\mathrm{W}_{1}, \mathrm{~W}_{2}=$ plant dry weight at the start and end of the study period respectively.

Destructive sampling of 60 trees in the experiment was carried out to develop regressions to be used on 360 standing trees in similar clones and weeding treatments. Photographs of all trees in the experiment were taken at each measurement time using a digital camera and their areas calculated using Metamorph image analysis [24] as explained by Kirongo [12], Kirongo et al. [13] and Mason et al. [18].

Regressions of crown areas on photographs vs. total tree biomass for destructively sampled trees were developed. Another set of regressions for leaf area (LA) vs. leaf weight (Lw) was developed for leaf samples collected from different crown parts of the destructively sampled trees as well as on standing trees [13]. The regressions were used to estimate standing trees' total biomass (W), total leaf areas (LA) [18] and total leaf weight (Lw).

From this information, mean ULR and mean LAR were calculated. From the computed values the terms of the RGR expansion and hence the RGR changes by age and tree size were calculated [12].

Total foliage amounts, foliage additions and losses were evaluated using a combination of image analysis techniques [24] and actual needle counts on 360 sampling units on 72 sample trees [12]. Estimates of needle mortality [12] were used to adjust for LA losses during the growth period, i.e. year 1-2 (= T1) and year 2-3 (= T2). Mean RGR was also calculated by accounting for carbon fixation potential as estimated by each leaf-age light use efficiency (light use efficiency in this context means the proportion of final products of photosynthesis the leaf will produce given same light conditions) [28]. The weighting procedure was done as follows; one-year old foliage was given a weighting of 1 , two-year old a weighting of 0.70 and threeyear old foliage a weighting of 0.40 [28].

Changes in RGR during the study period were then modelled using non-linear regression procedure in SAS [20]. The following equations were fitted to the data:

1. constant RGR model i.e. $\mathrm{RGR}=k$;

2. exponential equations (models) which allowed RGR to change with size and age:

$$
R G R=\ln (W) \times \frac{b}{T}
$$

derived from

$$
\begin{gathered}
\mathrm{W}=\exp \left(a \mathrm{~T}^{b}\right), \\
R G R=\frac{b}{T}
\end{gathered}
$$

derived from

$$
\mathrm{W}=a \mathrm{~T}^{b},
$$

and

$$
R G R=a+b \times \exp (-c \times W)
$$

an exponential decay function, where: $\mathrm{W}=$ plant dry weight, $\mathrm{T}=$ time and $a, b, c$ and $k$ are constants.

\section{RESULTS}

Mean relative growth rate of individual trees decreased both with tree age and size for all trees in the weeded treatments (Wc9, Wc3 and Wc0.75). Trees in the control (Wc0.03) recorded increased RGR with time and size, however (Fig. 1). RGR increased with increasing weed-free area per tree (Fig. 2). Clones 1 and 2 had higher RGRs than clone 3 in all weeded treatments (Fig. 2).

Weighting RGR to account for leaf-age differences and hence differences in C-fixation abilities led to slight increases in RGR in clones 1 and 2 but reductions in clone 3 (data not shown). The constant relative growth rate model, $\mathrm{RGR}=k$, was biased especially for tree size (Fig. 3).

Allowing RGR to vary with time and tree size gave good fits. Of the three functions fitted i.e. equations 11,13 and 15 , the exponential decay function, i.e. $R G R=a+b \times \exp (-c \times W)$ with dummy variables for weeding treatments and clones gave the best fits to the data. Plots of residuals vs the predicted values (not shown) and the independent variable (initial tree biomass) showed no apparent bias (Fig. 4). Using foliage biomass rather than tree biomass gave similar results (data not shown).

The dummy variables for weeding treatments were significant thus; $\mathrm{a}=\mathrm{a}_{0}+\mathrm{a}_{1} \times \mathrm{Wc0} 0.75, \mathrm{~b}=\mathrm{b}_{0}+\mathrm{b}_{1} \times \mathrm{Wc0} 03$ and $\mathrm{c}=$ $\mathrm{c}_{0}+\mathrm{c}_{1} \times \mathrm{Wc} 3$. The model outputs for equation 15 are summarized in Table I.

RGR trends plotted using the coefficients (Tab. I) output from the selected model (Eq. (15)) showed that trees in all weeded treatments (Wc9, Wc3 and Wc0.75) had a decline in RGR while those in the unweeded control (Wc0.03) had an increase in RGR with size (Fig. 5). Moreover, trees in Wc3 had a much faster decline in RGR than trees in Wc9, while those in $\mathrm{Wc0} 75$ had a lower asymptote in contrast to trees in 


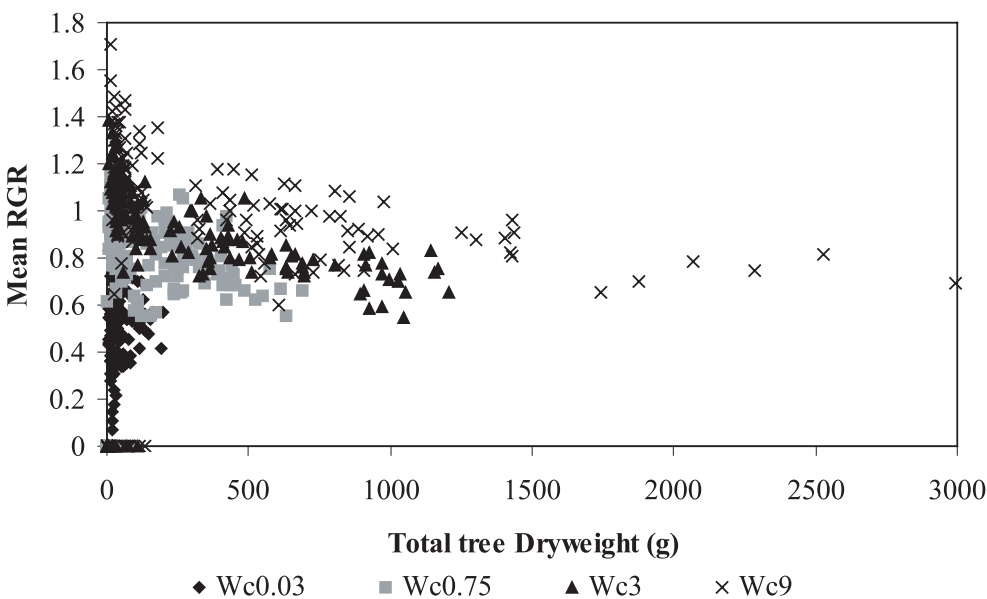

Figure 1. Mean relative growth rate $(\overline{R G R})$ versus initial tree above ground biomass for trees in all weeding treatments.

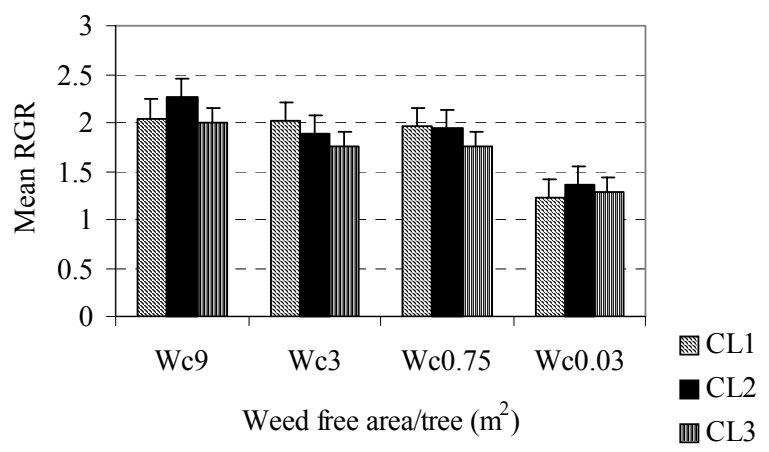

Figure 2. Unweighted mean relative growth rate of clones 1, 2 and 3 versus weed free area per tree $\left(\mathrm{m}^{2}\right)$ during the third growing season (age 3).

all the other treatments (Fig. 5). Weighting for leaf-age differences in C-fixation resulted in only slight increases in RGR in all weeding treatments (data not shown).

Clone 3 showed decreases in mean ULR with tree size during year 2-3 growth period while clones 1 and 2 showed slight increases in mean ULR during the same period (data not shown). Meanwhile, the leaf weight ratio (LWR) increased with increasing tree size in clone 3 but decreased with size in clones 1 and 2 (Fig. 6) during the same period. Clone 3 also showed increased LWR with age and increasing weed-free area per tree, while the opposite was true for clones 1 and 2 (data not shown).

Leaf area ratio increased with size in clone 3 but decreased in clones 1 and 2 (data not shown). Further analysis showed that clone 3 had increased LAR with age and with increasing weed-free area per tree, while clones 1 and 2 had weak trends showing decreases in LAR with size and tree age (data not shown).

Analysis on the possible causes of the decrease in RGR between year 2-3 season for trees in weeded environments showed there were decreases of up to $30 \%$ in ULR and upto $20 \%$ in LAR in some clones (Fig. 7). Meanwhile, trees in unweeded treatments had higher percentage increases in ULR (Fig. 7). In particular trees in the unweeded control belonging to clone 2 had highest percentage increases in RGR (40\% compared to $18 \%$ and $25 \%$ in clones 3 and 1 respectively). Trees in the unweeded control had the highest percent change in mean ULR during the same period; $70 \%$ in clone $2,55 \%$ in clone 1 and $10 \%$ in clone 3 (Fig. 7).

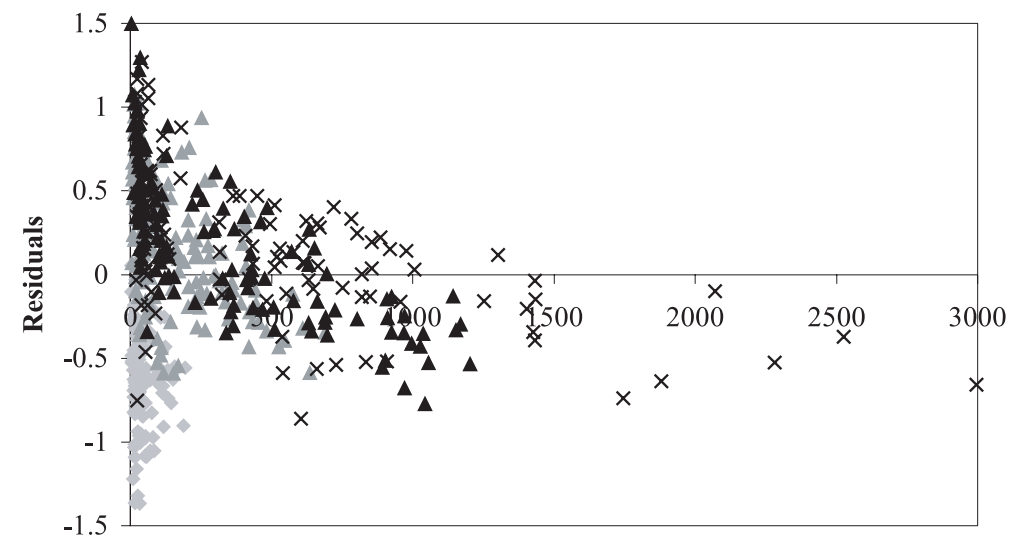

Initial Dry weight (g)

$\diamond \mathrm{Wc03} \Delta \mathrm{Wc0.75} \Delta \mathrm{Wc} 3 \quad \times \mathrm{Wc} 9$

Figure 3. Plot of residuals by initial tree size (biomass) for the $\mathrm{RGR}=\mathrm{k}$ model showing the bias with increasing tree size. 


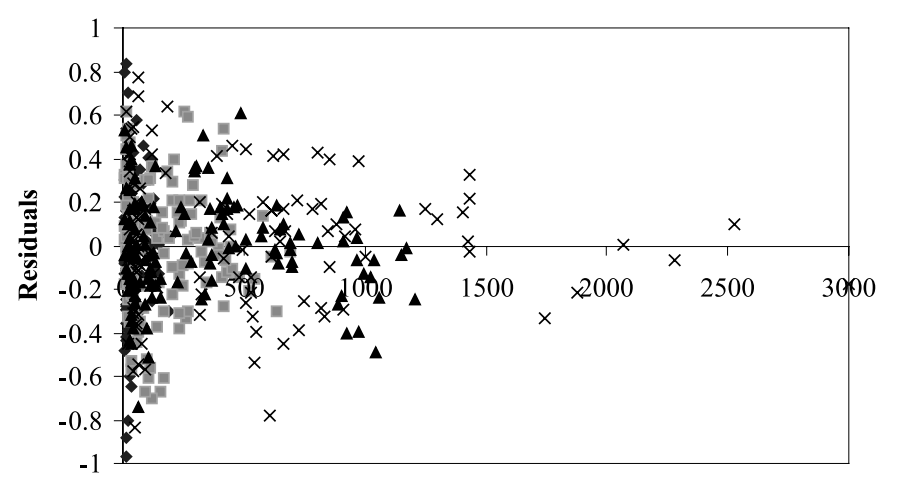

Initial tree dry weight $(\mathrm{g})$
$-\mathrm{Wc} 0.75 \quad=\mathrm{Wc} 0.75 \quad \Delta \mathrm{Wc} 3 \quad \times \mathrm{Wc} 9$

Figure 4. Plot of residuals versus predicted mean RGR for the exponential decay model showing apparent lack of bias.

LWR changes during the same period (year 2-3) increased with increasing competition in clones 1 and 2, but decreased in clone 3 . Trees in clones 1 and 2 in all weeding treatments had negative changes in LWR during the period year 2-3, while those in clone 3 had positive increases of between 15$25 \%$ (Fig. 8).

\section{DISCUSSION}

Relative growth rate decreased with size in all trees growing in weeded micro-environments and increased in trees in the unweeded control (Fig. 5). Blackman [2] postulated that for RGR to be constant ULR and LAR had to be constant with size. The trees in this study breached both these assumptions (Fig. 7). During the third growing season trees changed their LWR (Fig. 8) and their allometric ratios as well. Thus changes in allometry [4] may have contributed in part to the overall change in ULR and LAR and hence RGR.
Table I. Outputs of the exponential decay model fitted to the mean RGR data.

\begin{tabular}{|c|c|c|c|c|}
\hline Number of observation & Mean & Residual MSE & Skewness & Kurtosis \\
\hline 515 & 0.000072 & 0.085477 & -0.23551 & 0.651321 \\
\hline $\begin{aligned} \text { Coefficients: } & \mathrm{a} 0=1.7 \\
& \mathrm{~b} 1=-1 .\end{aligned}$ & $\begin{array}{ll}979, & \text { a1 } \\
5955, & \text { c0 }\end{array}$ & $\begin{array}{l}=-0.57142, \\
=0.00132\end{array}$ & $\begin{aligned} \mathrm{b} 0 & =0.940 \\
\mathrm{c} 1 & =0.003\end{aligned}$ & \\
\hline
\end{tabular}

Trees in the unweeded control had lowest RGR at the same size compared to those in weed free micro-environments. This may have been due to their low LA and hence photosynthetic capacities resulting in low LAR and reduced net assimilation rates. Trees in the control had proportionally more older foliage [13] than their counterparts growing in weeded environments. Old foliage is less efficient in C-fixation [15, 26, 27], a fact, which could explain in part the low productivity of trees in the unweeded controls. The weighting of RGR (to account for leaf age differences in carbon assimilation) showed little effect. This may suggest that the proportion of old foliage may be of little importance, an observation needing further study.

The decrease in RGR with time and especially tree size reported in this study serves to emphasize the observations made by others (e.g. Mason et al. [17], South [21]) that the belief of a constant RGR is fallacious. These results further support the suggestions made by Mason et al. [17] that growth analysts need to use equations which allow RGR to vary with tree age and size. The observation that the constant RGR model was highly biased for tree size (Fig. 3) further supports suggestions by Britt et al. [4] who postulated that RGR be compared on initial size basis rather than chronological age.

Mean RGR decreased with tree size and age in all weeded treatments but not the control. The increase in RGR with size in the unweeded controls may have been due to:

1. increased ULR with size (Fig. 7);

2. a possible increase in photosynthetic activity during the third growing season due to favourable weather (weather data not shown);

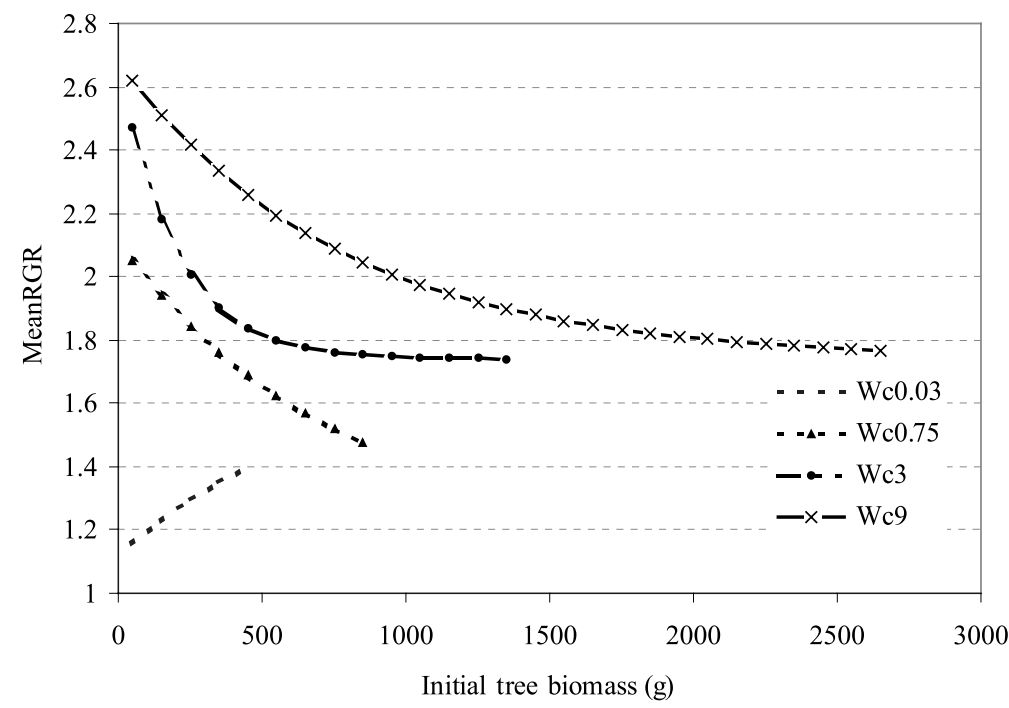

Figure 5. RGR trends with increasing initial tree biomass (g) for each weeding treatment showing increase in RGR with size for trees in unweeded treatment. 

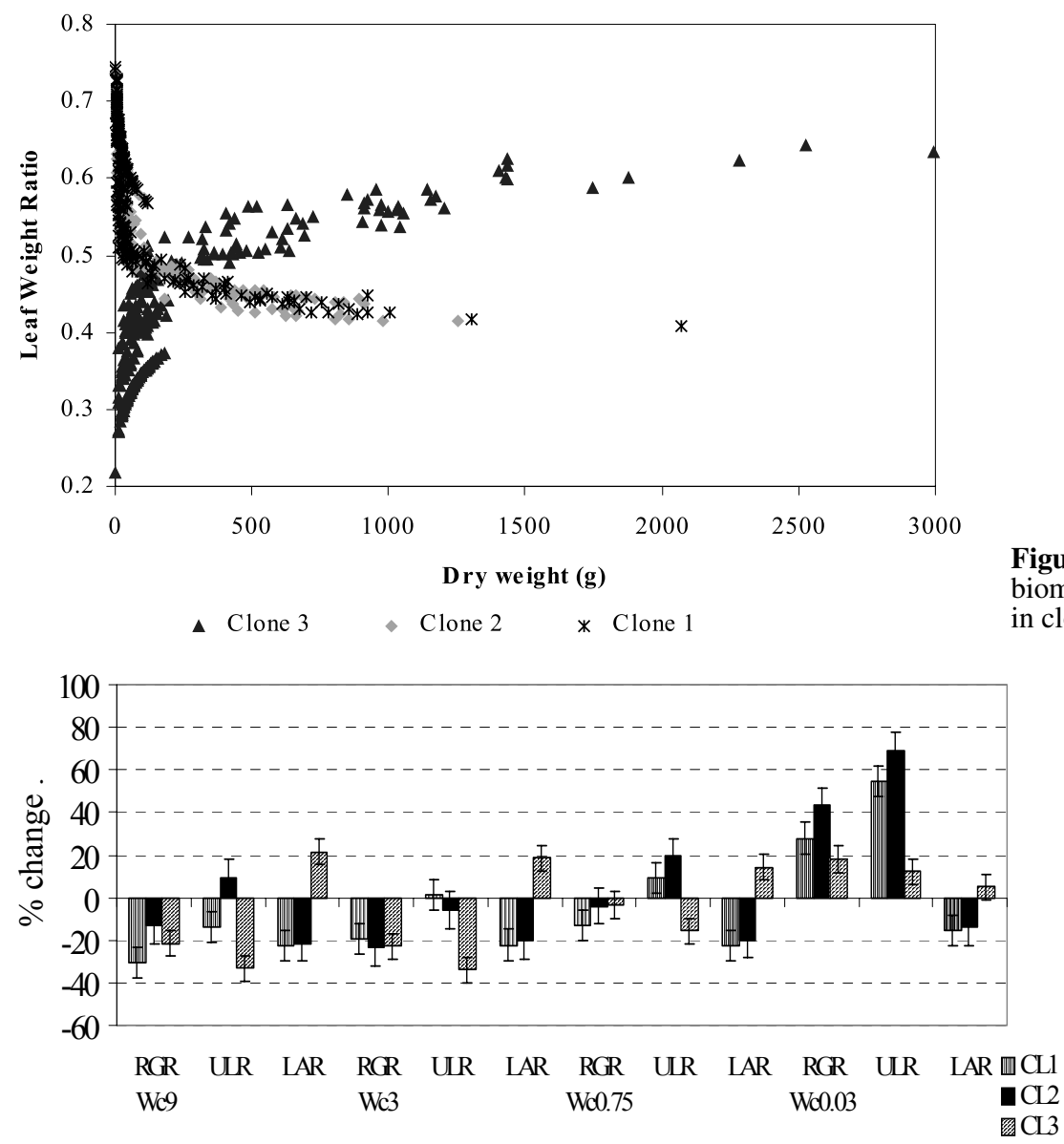

Figure 6. Mean Leaf weight ratio (LWR) versus initial tree biomass for clone 1, 2 and 3 showing an increase in LWR in clone 3 and a decrease in clones 1 and 2 .

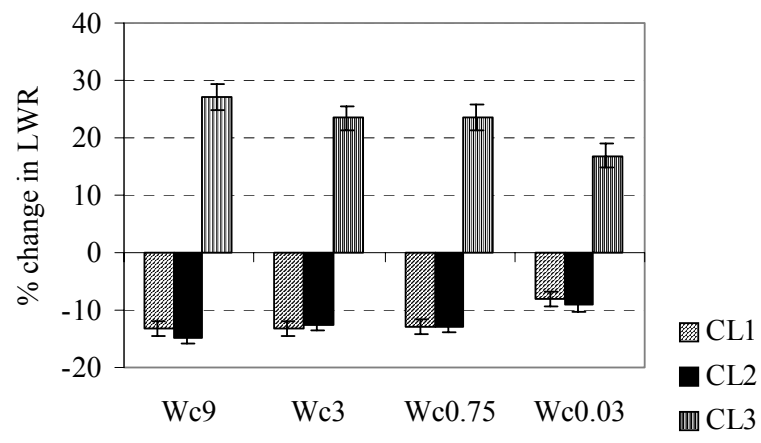

Figure 8. Percent changes in LWR for clones 1, 2 and 3 by increasing competition between year 2 and 3 .

\section{3. less self shading as a result of sparse crowns.}

By partitioning RGR into ULR and LAR, it was evident that the reasons for the decline in RGR for trees growing in weeded treatments were:

1. changes in allometry due to increases in LA in the third growing season;

2. possible self-shading in the crowns due to increased foliage amounts;

3. reduced LAR and ULR (Fig. 7);
Figure 7. Percent changes in mean RGR, ULR and LAR for clones 1,2 and 3 by increasing competition between year 2 and 3 .
4. increased proportions of physiologically young foliage which affected the trees' physiological age.

Self shading [4] has been said to be one of the causes of RGR decline in trees. Xu [28] reported significant self-shading in 5-year old radiata pine clones. However, South [21] reported RGR decreases in seedlings where self-shading may have been less important. In this study, the role of self-shading could not be explicitly determined and further studies on light conditions within canopies are recommended.

Clone 3 had lower RGR than the other 2 clones in all weeded environments. This may point to a different growth and above ground allocation strategy; a point supported by the increased LAR with size (Fig. 7), increased LWR (Fig. 6) and low ULR shown in this clone. The decrease in ULR in clone 3 and not in the other 2 clones may also imply that clone 3 spent more assimilates to nurture the new foliage formed during the third growing season before the foliage was fully mature and able to contribute positively to net assimilation [8]. Increased foliage amounts may also be a disadvantage in dry sites such as Dunsandell, leading to excessive evapotranspiration.

\section{CONCLUSIONS}

It is evident from this study therefore, that changes in RGR were influenced by ULR which depended on both the amounts 
and proportions of the different age classes of foliage on the crowns. High LAR (or LWR) led to increased RGR only in cases where ULR was also high. Changes in allometry due to increased new foliage influenced RGR through their effects on LA and overall photosynthetically active radiation (PAR) use efficiency as a result of a possible increase in self-shading. Changes in tree size were more correlated to changes in RGR than tree age.

This study showed clearly that the assumption of constant RGR is flawed. Quantifying the morphological and physiological terms of the RGR expansion showed that ULR was the main factor influencing RGR changes in this study. The main conclusions drawn were:

1. RGR changed with time and tree size in all treatments with the latter being more important than age in influencing RGR changes;

2. RGR decreased in trees in weeded environments but increased in trees in unweeded control;

3. The $\mathrm{RGR}=\mathrm{k}$ model was especially biased with tree size. An exponential decay function, $R G R=a+b \times \exp (-c \times W)$ gave the best fits for the RGR data;

4. ULR was the main factor influencing RGR changes in this study;

5. Clone 3 had a different growth and above ground allocation strategy and hence RGR trends to the other 2 clones studied.

\section{REFERENCES}

[1] Beets P.N., Pollock D.S., Accumulation and partitioning of dry matter in Pinus radiata as related to stand age and thinning, N. Z. J. For. Sci. 17 (1987) 246-271.

[2] Blackman V.H., The compound interest law and plant growth, Ann. Bot. 33 (1919) 353-360.

[3] Briggs G.E., Kidd F., West C., A quantative analysis of plant growth. I. Relative growth curve, Ann. Appl. Biol. 7 (1920) 103123.

[4] Britt J.R., Mitchell R.J., Zutter B.R., South D.B., Gjerstad D.H., Dickson J.F., The influence of herbaceous weed control and seedling diameter on six years of Loblolly pine growth - A classical growth analysis Approach, For. Sci. 37 (1991) 655-668.

[5] Burdon R.D., Sweet G.B., The problem of interpreting inherent differences in tree growth shortly after planting, in: Cannell M.G.R. (Ed.), Tree physiology and yield improvement, Academic Press, London, 1976, pp. 483-502.

[6] Causton D.R., A biologist's basic mathematics, Edward Arnold Publishers, 1983.

[7] Causton D.R., Venus J.C., The Biometry of plant growth, Edward Arnold Publishers, 1981.

[8] Dale E.J., The growth of leaves, Studies in Biology, No. 137, Edward Arnold publishers, 1982.

[9] Evans G.C., The quantitative analysis of plant growth, Blackwell Scientific publishers, Oxford, 1972.
[10] Gregory F.G., The effect of climatic conditions on the growth of barley, Ann. Bot. 40 (1926) 1-26.

[11] Hunt R., Plant growth curves: the functional approach to plant growth analysis, Edward Arnold publishers, 1982.

[12] Kirongo B.B., Modelling growth responses of juvenile radiata pine (Pinus radiata D. Don) clones subjected to different weed competition levels in Canterbury, New Zealand, Ph.D. thesis, University of Canterbury (Christchurch), New Zealand, 2000.

[13] Kirongo B.B., Mason E.G., Nugroho P.A., Interference mechanisms of pasture on the growth and fascicle dynamics of 3-year old radiata pine clones, For. Ecol. Manage. 159 (2002) 159-172.

[14] Ledig F.T., Perry T.O., Net assimilation rate and growth in loblolly pine seedlings, For. Sci. 15 (1969) 431-438.

[15] Leverenz J., Deans J.D., Ford E.D., Jarvis P.G., Milne R., Whitehead D., Systematic spatial variation of stomatal conductance in Sitka spruce plantation, J. Appl. Ecol. 19 (1982) 835-851.

[16] Mason E.G., Kirongo B.B., Responses of radiata pine clones to varying levels of pasture competition in a semiarid environment, Can. J. For. Res. 29 (1999) 934-939.

[17] Mason E.G., South D.B., Zutter B.R., Classical growth analysis for a computer age, in: Modelling regeneration success and Early growth of forest stands, Procs. IUFRO conference, Copenhagen, Denmark, 1996, pp. 221-230.

[18] Mason E., Kirongo B.B., Watt M.S., Richardson B., Mead D.J., Use of image analysis to estimate foliage masses of radiata pine clones and families subjected to varying levels of competition from weeds, Ann. For. Sci. (submitted).

[19] Menzies M.I., Klomp, B.K., Holden D.G., Optimal physiological age of propagules for use in Clonal forestry, in: Miller J.T. (Ed.), Procs. FRI/NZFP Forests Ltd., Clonal forestry workshop 1-2 May 1989, Rotorua, New Zealand, FRI Bulletin No. 160, 1991, pp. 142146.

[20] SAS Institute Inc., SAS/STATS, Guide for personal computers, version 6 Edition, Cary NC., SAS Institute, 1990.

[21] South D.B., Testing the hypothesis that mean relative growth rate eliminates size related growth differences in tree seedlings, N. Z. J. For. Sci. 21 (1991) 144-164.

[22] South D.B., Relative growth rates: A critique, South African For. J. 173 (1995) 43-48.

[23] Sweet G.B., Wareing P.F., The relative growth rates of large and small seedlings in forest tree species, Forestry Supplement, 1966, pp. 110-117.

[24] Universal Imaging Corporation, Metamorph Imaging system, Summary guide, Image -1/Metamorph Imaging System, Version 2 for MS windows, Universal Imaging Corporation, USA, 1995.

[25] Van den Driesche P., Van den Driesche R., Growth analysis, in: Van den Driesche R.'(Ed.), Mineral nutrition of Conifer seedlings, CRC press, Boca Raton, Florida, 1991.

[26] Watts W.R., Neilson R.E., Jarvis P.G., Photosynthesis in Sitka spruce (Picea sitchensis (Bong) CARR.): VII Measurements of stomatal conductance and ${ }^{14} \mathrm{CO}_{2}$ uptake in a forest canopy, J. Appl. Ecol. 13 (1976) 623-638.

[27] Woodman J.N., Variation of net photosynthesis within the crown of a large forest grown conifer, Photosynthetica 5 (1971) 50-54 (Abstracts).

[28] Xu H., Modelling Photosynthetic $\mathrm{CO}_{2}$ fixation among radiata pine clones with contrasting crown characterstics at age 5 at Dalethorpe, Canterbury, Ph.D. thesis, University of Canterbury, Christchurch, 2000. 